visit. Should the first level be above $7 \mathrm{mmol} / 1 \mathrm{(270} \mathrm{mg} / 100 \mathrm{ml})$ or any subsequent value exceed this figure, then the pill should normally not be commenced or continued. But even where there are no facilities for such analyses the well-trained prescriber, whether medical or non-medical, and the fully informed user should be able to balance the dangers of the pill against its benefits in each individual case.

JOHN GUILLEBAUD

Nuffield Department of Obstetrics and Gynaecology, John Radeliffe Hospital, Smith, M, fournal of Family Planning Doctors,
1975, 3, 14.

\section{Deaths in asthma}

SIR,-Since the "epidemic" of asthma deaths in the 1960s many asthmatic patients have died unnecessarily from this disease and Dr W N Dodds and his colleagues (8 November, p 345) describe another such example. Their patient used an isoprenaline inhaler frequently during her fatal attack and they infer that she might not have died if she had used a drug with more selective $\beta_{z \text {-adrenergic }}$ stimulant properties. I sympathise with their concern about this problem but believe that their patient died from asthma and not its treatment and that this is the case with the vast majority of asthma deaths.

It seems fairly certain that the major cause of the increased asthma mortality observed during the 1960s was indeed the introduction of the pressurised metered-dose isoprenaline inhaler, not because of any pharmacological properties of isoprenaline but because of its influence on therapeutic policy. The pressurised cannister inhaler provided, for the first time, an efficient method of delivering an effective bronchodilator drug to the bronchi. This device, because of its undoubted effectiveness, created in the minds of both doctors and patients a feeling of security which sadly proved to be totally unfounded. When the medical profession was alerted to the fact that an increase in asthma mortality had taken place and that at the same time there had been an increase in the use of the pressurised isoprenaline inhalers two major changes in the treatment of asthmatic patients in Britain took place. Firstly, more patients were admitted to hospital,1 presumably at a nearer stage of the disease, and secondly, there was a national increase in the prescription of corticosteroid drugs. ${ }^{2}$ It is therefore not in the least surprising that these actions were followed by a dramatic decrease in mortality from asthma, since the early administration of corticosteroid drugs and rapid admission of patients to hospital are the only effective ways of preventing death from acute asthma.

The reasons for a patient with severe asthma using a bronchodilator aerosol frequently during a fatal attack are self-evident, since unfortunately most patients who die from this disease do not have immediate access to any more efficient form of treatment. The medical profession has been slow to realise that all patients with asthma are at risk. This risk can be reduced by giving patients prednisolone to be taken on their own initiative at the onset of a severe attack whenever their bronchodilator aerosol proves to be ineffective and by decreasing to a minimum the time taken to admit patients to hospital.

Asthma can be a rapidly fatal disease, and until we accept this and stop trying to incriminate our of ten inadequate therapeutic attempts to control it there can be little hope of us decreasing asthma mortality in the future.

\section{Graham K Crompton}

Respiratory Unit, Northern General Hospital, Edinburgh

1 Dollery, C T, Annals of Allergy, 1973, 31, 38. Proceedings of the Asthma Research Council Symposium on Evaluation of Bronchodilator tion and Research in Therapeutics, 1974.

\section{Management of acute asthma}

SIR,-I read with interest your leading article on this subject (11 October, p 65), and was fascinated to note that one object is to correct arterial hypoxaemia by oxygen therapy "to maintain the $\mathrm{PaO}_{2}$ between 7.95 and $10.59 \mathrm{kPa}$." I suspect you discovered these interesting numbers by dividing 60 and 80 respectively by the relevant conversion from $\mathrm{mm} \mathrm{Hg}$ to $\mathrm{kPa}$. Surely you are aware that the lower limit of "safety" for $\mathrm{PaO}_{2}$ is highly speculative and the higher limit, given presumably to avoid oxygen toxicity, is even more a matter of debate. Would you not settle for a range of $8-10$ (or 11 , or 12 , or 20) $\mathrm{kPa}$ ? If so there is a possibility that some of your readers might remember what you have written, whereas the range you give will be immediately forgotten, I hope.

Further down you define hypercapnia as characterised by a $\mathrm{PaCO}_{2}$ greater than 7.95 $\mathrm{kPa}$. Do you really mean this?

\section{KENNETH B SAUNDERS}

Department of Medicine,

Middlesex Hospital,

** This illustrates the sort of difficulty that is bound to arise during the transition period when people are still thinking in traditional units but dutifully converting their values into SI units. The reason for the rather curious values given in kilopascals in ou article would have been made clear had we not inadvertently omitted to give the values in millimetres of mercury too. In answer to Dr Saunders's further query a $\mathrm{PaCO}_{2}$ persistently above $7.95 \mathrm{kPa}(60 \mathrm{~mm} \mathrm{Hg})$ is, in our view, frequently an indication for assisted ventilation.-ED, $B M \mathcal{F}$.

\section{Rabies}

SIR,-The attention drawn to the importance of rabies in man by your recent excellent leading article (27 September, p 721) accompanying the article on treatment by $\mathrm{Mr} \mathrm{L}$ Klenerman and others (p 740) and followed by some interesting correspondence has been a welcome addition to the publicity given by the mass media to the importance of keeping rabies as a disease of animals out of the United Kingdom.

However, in my opinion, the various contributors may have placed in the background the first decision with which a medical ad- viser will be faced on being informed that a patient has been bitten by a dog while on holiday in a country in which rabies occurs or is endemic. Indeed such a case was spotlighted recently by Scottish television. As modern vaccines such as the duck embryo vaocine have been shown to be safe and relatively free of pain on injection it seems to me that there must be one answer only, and that is to embark on post-incident vaccination with the use of antirabies serum or human immunoglobulin when available. There is well-documented case evidence to show that if one waits until the fate of the dog is known before starting vaccination the patient may die. In fact patients have died even when vaccination has been started immediately.

One of the patients who died in London this summer had been bitten on the lower lip, causing significant haemorrhage, by a stray puppy apparently playful and normal. This patient had received medical advice immediately after the incident to the effect that as the puppy had appeared normal there was no need to treat the wound or to vaccinate against rabies. This occurred in a country where rabies is endemic in the canine population, but any medical adviser in Britain may be faced with a similar decision by a tourist returning overnight from such a country having been bitten by a dog the previous day.

Finally, may I use the courtesy of your columns further to appeal to the medical profession to supplement the continuing efforts made by the customs officers and veterinarians to detect any dog, cat, or other animal imported illegally into Britain? This dreadful practice is known to occur at least 100 times each year and has sometimes been detected by a conscientious neighbour or even given away by the confident boast of the perpetrator, not necessarily over a drink!

IAN MCINTYRE

University of Glasgow Veterinary Faculty, Glasgow

\section{Drugs for addicts}

SIR,-I was very interested in the letter from Dr A H de C Freed (20 September, p 703), as he so exactly expresses views which I have held for a long time. Although in no way an expert on drug addiction and treatment, I have discussed the subject with many who are. They always leave me with a feeling of vague disquiet.

To the question, What percentage of cures do you achieve? one often gets a guarded answer. "It's difficult to give a definite figure, but we seem to do quite well. Some move away and we lose sight of them; but we do have a lot of successes." How many can be considered absolutely permanent? "Well, many keep off drugs for six months or even a year, but of course some do revert" How many revert? "It's difficult to say, but probably quite a few do." Of course it's all very difficult, but it seems to me that the statistics tend to be very inaccurate.

Certain questions and points should be kept in mind about addicts, at any rate those on heroin or other hard drugs: (1) Is our kindly system of dealing with these people by prescribing their drugs on the NHS a really effective one? It does probably reduce 